\title{
Factors associated with overweight in children in Rasht, Iran: gender, maternal education, skipping breakfast and parental obesity
}

\author{
Moshen Maddah* and Bahareh Nikooyeh \\ Department of Human Nutrition, School of Public Health, Guilan University of Medical Sciences and Health \\ Services, PO Box 41635-3197, Rasht, Islamic Republic of Iran
}

Submitted 18 September 2008: Accepted 13 May 2009: First published online 23 June 2009

\begin{abstract}
Objective: The present study aimed to investigate the determinants of overweight and obesity among 6- to 11-year-old schoolchildren in Rasht, Iran.

Design: Cross-sectional survey. Data on age, weekly frequency of skipping breakfast, physical activity and hours of television viewing were collected. Information on birth weight, parental age, parental educational levels, parental weight and height, and mother's employment status were gathered through selfadministrated questionnaires given to the parents.

Setting: Elementary schools in Rasht.

Subjects: A total of 6635 children ( 3551 boys and 3084 girls) attending elementary schools in Rasht were studied.

Results: The overall prevalence of overweight was $11 \cdot 5 \%$ and $15 \cdot 0 \%$ for boys and girls, respectively; while the overall prevalence of obesity was $5.0 \%$ and $5.9 \%$, respectively. Children with more educated mothers had a higher prevalence of overweight than children with less educated mothers. Logistic regression analysis showed that children with overweight/obese parents, children with more educated mothers and children who often skipped breakfast were more prone to overweight and obesity.

Conclusions: These data suggest that overweight and obesity is a public health concern in this age group in Rasht. The observed sex and social differences in the prevalence of overweight and obesity call for policy makers' attention.
\end{abstract}

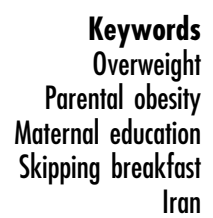

Keywords

Overweight

Parental obesity

Skipping breakfast

Iran
Childhood overweight and obesity is on the rise throughout the world, and many developing countries are experiencing a double burden of malnutrition ${ }^{(1,2)}$. Childhood seems to be one of the critical periods in the development of obesity ${ }^{(3)}$. Overweight and obesity among children and adolescents is associated with morbidity and mortality in adulthood ${ }^{(4,5)}$. While the steepest increases in obesity prevalence are now occurring in children of low socio-economic status in developed countries $^{(6,7)}$, there is less information from developing countries.

Iran is a middle-income country experiencing rapid epidemiological transition ${ }^{(8)}$, where high prevalences of hypertension, obesity and type 2 diabetes have been documented in the population ${ }^{(9)}$. Obesity is now the most prevalent nutritional disease among children and adolescents in $\operatorname{Iran}^{(10,11)}$. Recent studies have also shown that metabolic syndrome is highly prevalent among children and adolescents in $\operatorname{Iran}^{(12)}$. Population studies of the elementary school age group are needed not only to document overall trends in obesity, but also to explore if any subgroup susceptibility exists in the population.

The objectives of the present study were to provide current data on the prevalence of overweight and obesity by gender, maternal education and some lifestyle factors in the population of elementary-school students in Rasht, northern Iran.

\section{Methods and subjects}

The study was designed to evaluate the prevalence of overweight/obesity and to investigate the association of some biological and social factors with childhood overweight and obesity among boys and girls of elementary school age in urban areas in Rasht, northern Iran. The study population was 6- to 11-year-old children studying in elementary schools in Rasht, the main city of Guilan province. Between October 2006 and March 2007 a random sample of 6760 students was selected from all 
elementary schools in Rasht. Selection of the subjects was initially made by school level, not by age of the students. Since the age of 125 students was not in the range of the protocol, they were excluded; thus 6635 observations ( 3551 boys and 3084 girls) were included in data analysis.

Information on child's age, birth rank, skipping breakfast, physical activity, hours of television viewing, birth weight (only for girls), parental age, parental educational levels and mother's employment status was gathered using a self-administrated questionnaire given to the parents. Current body weight and height of the parents were self-reported. Breakfast frequency was asked as 'How many times during weekdays do you eat breakfast?' A physical activity questionnaire was developed for the study that asked participants to recall the number of hours per week during which they participated in any structured physical activity or team sport within the last 6 months. Response categories ranged from 0 to $\geq 8 \mathrm{~h} /$ week. Commuting between home and school was asked as five categories $(<5 \mathrm{~min} / \mathrm{d}, 5-15 \mathrm{~min} / \mathrm{d}, 15-30 \mathrm{~min} / \mathrm{d}$, $30-45 \mathrm{~min} / \mathrm{d}$ and $>45 \mathrm{~min} / \mathrm{d}$ ). The time spent watching television and playing computer/video games was recorded for each day of a typical week and divided into three classes $(<3 \mathrm{~h} / \mathrm{d}, 3-5 \mathrm{~h} / \mathrm{d},>5 \mathrm{~h} / \mathrm{d})$. Anthropometric measurements were performed in lightly dressed children without shoes in the morning. Body weight was measured to the nearest $0 \cdot 1 \mathrm{~kg}$ using a balanced-beam scale; height was measured to the nearest $0.5 \mathrm{~cm}$ with the child standing up and his/her head, back and buttocks on the vertical land of the height gauge. Age- and sex-specific BMI cut-offs proposed by the International Obesity Taskforce were used to define overweight and obesity ${ }^{(13)}$. Parental overweight and obesity was defined as BMI $\geq 25 \mathrm{~kg} / \mathrm{m}^{2}$ and $\geq 30 \mathrm{~kg} / \mathrm{m}^{2}$, respectively, for either of the parents.

All parents gave written consent for participation in the study. The study protocol was approved by the ethical committee of Guilan University of Medical Sciences.

\section{Statistical analysis}

Differences in the prevalence of overweight and obesity were tested using $\chi^{2}$ statistics. In data analysis, the mother's level of education was classified as $<5$ years of schooling, 5-11 years of schooling, high-school diploma
(12 years of schooling) and college study ( $>12$ years of schooling). Logistic regression analysis was used to determine the predictors of overweight and obesity in the study children. Maternal educational level, sex, age, television viewing, mother's employment, paternal overweight/ obesity, walking and skipping breakfast were considered as categorical variables and birth weight was considered as continuous variables in the model.

Values are given as means with $95 \%$ confidence intervals or standard deviation. $P$ values $<0.05$ were considered to indicate significance. Analyses were performed using the SPSS for Windows statistical software package version 10·01 (SPSS Inc., Chicago, IL, USA).

\section{Results}

Mean BMI and the percentage of overweight and obesity among boys and girls as a function of age are given in Table 1 . The overall prevalence of overweight was $11.5 \%$ and $15.0 \%$ for boys and girls, respectively; the overall prevalence of obesity was $5.0 \%$ and $5.9 \%$, respectively. Girls and boys with more educated mothers had a higher prevalence of overweight and obesity than girls and boys with less educated mothers (Table 2).

In the present study, the mean age of the mothers and fathers was 34.8 (sD 5.6) years and 39.3 (SD 5.9) years, respectively. Overweight and obesity prevalence among the mothers was $42 \cdot 7 \%$ and $24.2 \%$, respectively; and among the fathers was $43 \cdot 3 \%$ and $12 \cdot 2 \%$, respectively. Weight gain after marriage was reported by 4687 parents. Mean weight gain for the mothers and fathers in the study was 13.1 (SD 9.5) $\mathrm{kg}$ and 9.1 (SD 8.7) $\mathrm{kg}$, respectively. Overweight and obesity was most common in those children whose both parents were overweight or obese (Table 2).

Figure 1 shows that overweight and obesity was more common in those who skipped breakfast than those who often had breakfast at home; the difference was significant in boys and girls.

Results of the logistic regression analysis showed that the risk of overweight/obesity was higher for girls and for children whose parents were overweight or obese.

Table $1 \mathrm{BMI}$ and prevalence of overweight and obesity according to age group in boys and girls in Rasht, Iran

\begin{tabular}{|c|c|c|c|c|c|c|c|c|c|c|}
\hline \multirow[b]{3}{*}{ Age group } & \multicolumn{5}{|c|}{ Girls (n 3084) } & \multicolumn{5}{|c|}{ Boys ( $n$ 3551) } \\
\hline & \multirow[b]{2}{*}{$n$} & \multicolumn{2}{|c|}{ BMI $\left(\mathrm{kg} / \mathrm{m}^{2}\right)$} & \multirow[b]{2}{*}{ Overweightt (\%) } & \multirow[b]{2}{*}{ Obeset (\%) } & \multirow[b]{2}{*}{$n$} & \multicolumn{2}{|c|}{ BMI $\left(\mathrm{kg} / \mathrm{m}^{2}\right)$} & \multirow[b]{2}{*}{ Overweightt (\%) } & \multirow[b]{2}{*}{ Obeset (\%) } \\
\hline & & Mean & $95 \% \mathrm{Cl}$ & & & & Mean & $95 \% \mathrm{Cl}$ & & \\
\hline 6 years & 232 & $15 \cdot 5$ & $15 \cdot 3,15 \cdot 8$ & $10 \cdot 8$ & $5 \cdot 6$ & 264 & $16 \cdot 0$ & $15 \cdot 5,16 \cdot 7$ & $9 \cdot 1$ & $7 \cdot 6$ \\
\hline 7 years & 542 & $15 \cdot 8$ & $15 \cdot 6,16 \cdot 0$ & $11 \cdot 1$ & $6 \cdot 3$ & 657 & $15 \cdot 7$ & $15 \cdot 5,15 \cdot 9$ & $7 \cdot 9$ & $4 \cdot 6$ \\
\hline 8 years & 566 & $16 \cdot 2$ & $16 \cdot 0,16 \cdot 4$ & $11 \cdot 7$ & 4.9 & 684 & $16 \cdot 2$ & $15 \cdot 9,16 \cdot 4$ & $11 \cdot 1$ & $4 \cdot 7$ \\
\hline 9 years & 592 & $17 \cdot 0$ & $16 \cdot 7,17 \cdot 2$ & $16 \cdot 4$ & $4 \cdot 7$ & 798 & $16 \cdot 2$ & $15 \cdot 9,16 \cdot 5$ & $11 \cdot 8$ & $5 \cdot 5$ \\
\hline 10 years & 613 & $18 \cdot 0$ & $17 \cdot 7,18 \cdot 3$ & $20 \cdot 1$ & $6 \cdot 2$ & 737 & $17 \cdot 3$ & $17 \cdot 1,17 \cdot 6$ & 14.9 & $4 \cdot 7$ \\
\hline 11 years & 539 & $18 \cdot 7$ & $18 \cdot 4,19 \cdot 0$ & $17 \cdot 3$ & $7 \cdot 2$ & 411 & $17 \cdot 9$ & $17 \cdot 6,18 \cdot 2$ & $12 \cdot 7$ & $4 \cdot 1$ \\
\hline
\end{tabular}

tUsing the International Obesity Taskforce definition of overweight and obesity ${ }^{(13)}$. 
Table 2 Prevalence of overweight and obesity according to maternal educational level and parental weight status in boys and girls in Rasht, Iran

\begin{tabular}{|c|c|c|c|c|}
\hline & \multicolumn{2}{|c|}{ Girls $(n$ 3084)* } & \multicolumn{2}{|c|}{ Boys ( $n$ 3551) } \\
\hline & Overweightt (\%) & Obeset (\%) & Overweightt (\%) & Obeset (\%) \\
\hline \multicolumn{5}{|l|}{ Maternal educational level } \\
\hline$<5$ years $(n 1483)$ & $13 \cdot 2$ & $4 \cdot 3$ & $8 \cdot 7$ & $3 \cdot 6$ \\
\hline $5-11$ years $(n 1948)$ & $14 \cdot 2$ & $5 \cdot 0$ & $12 \cdot 2$ & $4 \cdot 7$ \\
\hline 12 years $(n 2512)$ & $16 \cdot 3$ & $7 \cdot 1$ & $12 \cdot 0$ & $5 \cdot 8$ \\
\hline$>12$ years $(n 689)$ & $17 \cdot 6$ & $7 \cdot 3$ & $14 \cdot 5$ & $5 \cdot 4$ \\
\hline \multicolumn{5}{|l|}{ Parental weight status } \\
\hline Both normal weight ( $n$ 697) & $9 \cdot 7$ & $1 \cdot 6$ & $5 \cdot 5$ & $2 \cdot 5$ \\
\hline Mother is overweight or obese $(n 1430)$ & $14 \cdot 3$ & $5 \cdot 0$ & $10 \cdot 2$ & $3 \cdot 1$ \\
\hline Father is overweight or obese ( $n$ 811) & $14 \cdot 3$ & 4.9 & $9 \cdot 8$ & $4 \cdot 4$ \\
\hline Both overweight or obese $(n$ 1749) & $20 \cdot 5$ & $10 \cdot 8$ & $16 \cdot 4$ & $8 \cdot 0$ \\
\hline
\end{tabular}

*Overweight and obesity were significantly more prevalent in girls than boys $(P<0.05$ to $P<0.0001)$. +Using the International Obesity Taskforce definition of overweight and obesity ${ }^{(13)}$.

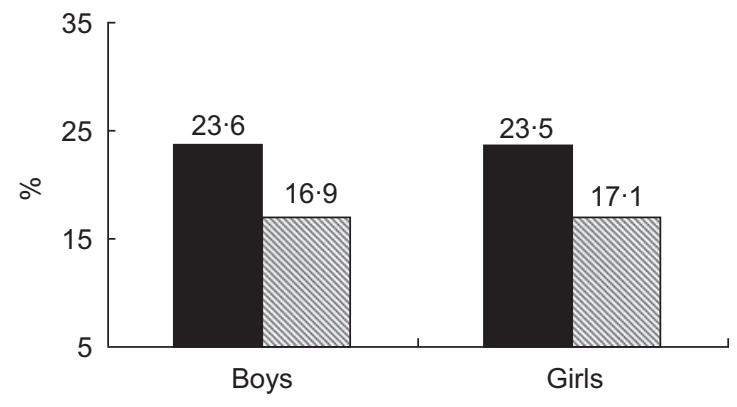

Fig. 1 Prevalence of overweight/obesity by breakfast skipping

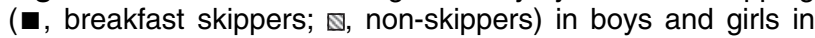
Rasht, Iran. Significant difference between breakfast skippers and non-skippers $(P<0.001)$

In addition, higher maternal education and skipping breakfast were positively related to overweight/obesity in these children (Table 3).

\section{Discussion}

The present study highlights the importance of overweight and obesity among 6- to 11-year-olds in Rasht as a public health issue and indicates that it is necessary to consider the impact of overweight during childhood on adult morbidity. The present data indicated that girls were more likely to be overweight and obese than boys. Similar findings were reported in the south of Iran, where obesity was significantly less prevalent in boys $(3 \cdot 3 \%)$ than girls $(6 \cdot 1 \%)$ aged $6 \cdot 5-11 \cdot 5$ years $(P<0 \cdot 001)^{(14)}$. The high prevalence of cardiovascular risk factors in overweight and obese children and the positive correlation of these factors with obesity severity emphasize the need for prevention and control of childhood obesity from early stages ${ }^{(15)}$.

Studies performed in developed countries have demonstrated a negative relationship between socioeconomic status and overweight among children and adolescents $^{(6,7)}$. There is, however, little information on the association of socio-economic status and overweight among children in developing countries. In the present study, overweight and obesity was more common in boys and girls with more educated mothers than in those with less educated mothers. In multivariable analysis maternal educational level was independently related to overweight after controlling for other variables including mother's employment status. We do not know why more educated Iranian families are less concerned about the ideal body weight for their children than less educated families. It has been reported previously that there is less social pressure for conforming to an ideal body image in Iran, as an Islamic country ${ }^{(16)}$. Further studies are needed to address the hypothesis that in Islamic societies women's dressing style may lessen their concern about thinness and dieting.

In accordance with other studies ${ }^{(17,18)}$, the present study also showed that when a broad range of factors is taken into consideration simultaneously, skipping breakfast was associated with overweight/obesity in children. Findings from the current study showed that overweight/obesity was more prevalent among those usually skipped breakfast than in those who usually had their breakfast at home $(23.5 \% \mathrm{v}$. $17 \cdot 0 \%, \quad P<0 \cdot 0001)$. Skipping breakfast was positively related to overweight after controlling for other measured factors. Skipping breakfast may be related to the intake of high-energy foods during school hours in these adolescents.

Parental overweight ${ }^{(19)}$ and especially maternal overweight ${ }^{(20)}$ has been reported to be related to childhood overweight in Western countries. The present study showed that both paternal and maternal overweight and obesity were important predictors of overweight and obesity in the study children. In addition to genetic resemblance, family members show similar behavioural risk factors associated with overweight and obesity. Mean weight gain after getting married in the study parents was rather high and its association with childhood obesity suggest that lifestyle changes should be aimed at all members of a family. 
Table 3 Logistic regression analysis of the potential risk factors for overweight/obesity in girls and boys in Rasht, Iran, adjusted for each variable (age, sex, maternal educational level, television viewing, birth rank, mother's employment, parental overweight/obesity, walking, skipping breakfast as categorical variables and birth weight as continuous variable)

\begin{tabular}{|c|c|c|c|c|c|}
\hline & $\beta$ & SE & OR & $95 \% \mathrm{Cl}$ & $P$ value \\
\hline Girls & $0 \cdot 32$ & 0.08 & $1 \cdot 3$ & $1 \cdot 1,1 \cdot 6$ & 0.0001 \\
\hline Maternal overweight/obesity & 0.50 & $0 \cdot 17$ & $1 \cdot 6$ & $1 \cdot 1,2 \cdot 3$ & 0.003 \\
\hline Paternal overweight/obesity & 0.52 & $0 \cdot 13$ & $1 \cdot 7$ & $1 \cdot 3,2 \cdot 2$ & 0.001 \\
\hline Both parents overweight/obese & $1 \cdot 20$ & $0 \cdot 14$ & $3 \cdot 3$ & $2 \cdot 5,4 \cdot 4$ & 0.0001 \\
\hline Skipping breakfast & $0 \cdot 37$ & 0.08 & $1 \cdot 4$ & $1 \cdot 2,1 \cdot 7$ & 0.0001 \\
\hline \multicolumn{6}{|l|}{ Maternal education } \\
\hline $5-11$ years & 0.52 & $0 \cdot 13$ & $1 \cdot 6$ & $1 \cdot 3,2 \cdot 2$ & 0.0001 \\
\hline 12 years & 0.63 & $0 \cdot 12$ & $1 \cdot 9$ & $1 \cdot 4,2 \cdot 4$ & 0.0001 \\
\hline$>12$ years & 0.72 & $0 \cdot 15$ & $2 \cdot 0$ & $1 \cdot 5,2 \cdot 8$ & 0.0001 \\
\hline Constant & $-2 \cdot 60$ & 0.23 & - & - & 0.0001 \\
\hline
\end{tabular}

There are no data investigating physical activity in Iranian children. The data collected in the present study indicated that $85 \%$ of the subjects did no exercise during school days or holidays, and the average time spent watching television was quite high $(3.9(\mathrm{SD} 1.7) \mathrm{h} / \mathrm{d})$. Although no link with inactivity and overweight was found in the study, these results confirm that the study population had generally inactive behaviours.

There are a number of possible limitations to the current study. Owing its cross-sectional nature, the temporal nature of the observed relationships cannot be determined. Furthermore, parental body weight and height were self-reported and there are no data to show whether self-reported weight and height are reliable in Iran. Also, no direct data on economic status, such as income, was collected.

In conclusion, the present data showed that overweight and obesity is prevalent among elementary-school children, especially in girls and in upper social class, in Rasht, Iran. Policy makers and health professionals should pay special attention to children's health and preventing obesity in children should be regarded as an important public health priority in the region.

\section{Acknowledgements}

The work was supported financially by Guilan University of Medical Sciences, Rasht, Iran. There is no conflict of interest. M.M. designed the study, conducted the data analysis and wrote the paper. B.N. helped in data collection and data analysis. The authors wish to thank the students and their parents for their participation in the study, and to extend their appreciation to the school personnel for their cooperation in collecting the data.

\section{References}

1. de Onis M \& Blossner M (2000) Prevalence and trends of overweight among preschool children in developing countries. Am J Clin Nutr 72, 1032-1039.

2. Popkin BM (2001) The nutrition transition and obesity in the developing world. J Nutr 131, 871S-873S.
3. Dietz WH (1994) Critical periods in childhood for development of obesity. Am J Clin Nutr 59, 955-959.

4. Guo SS, Wu W, Chumlea WC \& Roche AF (2002) Predicting overweight and obesity in adulthood from body mass index values in childhood and adolescents. Am J Clin Nutr 76, 653-658.

5. Van Dam RM, Willet WC, Manson JE \& Hu FB (2006) The relation between overweight in adolescence and premature death in women. Ann Intern Med 145, 91-97.

6. Wake M, Hardy P, Canterford L, Sawyer M \& Carlin JB (2007) Overweight, obesity and girth of Australian preschoolers: prevalence and socioeconomic correlates. Int J Obes (Lond) 31, 1044-1051.

7. Goodman E, Alder NE, Daniel SR, Morrison JA, Slap GB \& Dolan LM (2003) Impact of objective and subjective social status in biracial cohort of adolescents. Obes Res 11, 1018-1026.

8. Ghassemi H, Harrison G \& Mohammad K (2002) An accelerated nutrition transition in Iran. Public Health Nutr 5, 149-155.

9. Azizi F, Salehi P, Etemadi A \& Zahedi-Asl S (2003) Prevalence of metabolic syndrome in an urban population: Tehran Lipid and Glucose Study. Diabetes Res Clin Pract 61, 29-37.

10. Mohammadpour-Ahranjani B, Rashidi A, Karandish M, Eshraghian MR \& Kalantri N (2004) Prevalence of overweight and obesity in adolescent Tehrani students, 2000-2001: an epidemic health problem. Public Health Nutr 7, 645-648.

11. Maddah M (2007) Overweight and obesity among school girls in Rasht: more overweight in lower social class. Public Health Nutr 10, 450-453.

12. Esmailzadeh A, Mirmiran P, Azadbakht L, Etemadi A \& Azizi F (2006) High prevalence of the metabolic syndrome in Iranian adolescents. Obes Res 14, 377-382.

13. Cole TJ, Bellizzi MC, Flegal KM \& Dietz WH (2000) Establishing a standard definition for child overweight and obesity worldwide: international survey. BMJ 320, 1240-1246.

14. Ayatollahi SM \& Mostajabi F (2007) Prevalence of obesity among schoolchildren in Iran. Obes Rev 8, 289-291.

15. Hamidi A, Fakhrzadeh H, Moaweri A, Pourebrahim R, Heshmat R, Noori M, Rezaeikhah Y \& Larijani B (2006) Obesity and associated cardiovascular risk factors in Iranian children: a cross-sectional study. Pediatr Int 48, 566-571.

16. Maddah M, Eshraghian MR, Djazayery A \& Mirdamadi R (2003) Association of body mass index with educational level in Iranian men and women. Eur J Clin Nutr 57, 819-823.

17. Vanelli M, Iovane B, Bernardini A, Chiari G, Errico MK, Gelmetti C, Corchia M, Ruggerini A, Volta E \& Rossetti S; Students of the Post-Graduate School of Paediatrics, University of Parma (2005) Breakfast habits of 1,202 
northern Italian children admitted to a summer sport school. Breakfast skipping is associated with overweight and obesity. Acta Biomed 76, 79-85.

18. Ortega RM, Requejo AM, Lopez-Sobaler AM, Quintas ME, Andrés P, Redondo MR, Navia B, López-Bonilla MD \& Rivas $\mathrm{T}$ (1998) Difference in the breakfast habits of overweight/ obese and normal weight schoolchildren. Int J Vitam Nutr Res 68, 125-132.
19. Francis LA, Ventura AK, Marini M \& Birch LL (2007) Parent overweight predicts daughters' increase in BMI and disinhibited overeating from 5 to 13 years. Obesity (Silver Spring) 15, 1544-1553.

20. Johanssen DL, Johanssen NM \& Specker BL (2006) Influence of parents' eating behaviors and child feeding practice on children's weight status. Obesity (Silver Spring) 14, 431-439. 